\title{
Effect of Phosphite on Tomato and Pepper Plants and on Susceptibility of Pepper to Phytophthora Root and Crown Rot in Hydroponic Culture
}

\author{
H. Förster, J. E. Adaskaveg, D. H. Kim, and M. E. Stanghellini, Department of Plant Pathology, University of \\ California, Riverside 92521
}

\begin{abstract}
Förster, H., Adaskaveg, J. E., Kim, D. H., and Stanghellini, M. E. 1998. Effect of phosphite on tomato and pepper plants and on susceptibility of pepper to Phytophthora root and crown rot in hydroponic culture. Plant Dis. 82:1165-1170.

Tomato and pepper plants were grown hydroponically in a greenhouse using phosphate or technical and commercial formulations of phosphite as sources of phosphorus nutrition to determine the effects on plant development and susceptibility to Phytophthora root and crown rot. Phosphite-treated tomato and pepper plants were deficient of phosphate and developed phosphorus-deficiency symptoms. Growth of plants (leaf area and leaf, stem, and root dry weights) that were fertilized with phosphite was significantly $(P<0.05)$ reduced compared with phosphatefertilized plants. In Phytophthora capsici-inoculated pepper plants, incidence of Phytophthora crown rot was significantly reduced in phosphite-treated plants compared with no phosphorus or phosphate-treated plants. Incidence of crown rot in pepper plants treated with $1 \mathrm{mM}$ phosphate plus $0.3 \mathrm{mM}$ phosphite was intermediate between plants treated with only phosphite $(1 \mathrm{mM}$ or $0.1 \mathrm{mM})$ and plants treated with phosphate $(1 \mathrm{mM})$.
\end{abstract}

Additional keywords: phosphonate fungicides, phosphorous acid

Phosphorus nutrition of plants is provided in various forms of phosphates, the salts of phosphoric acid. Although phosphates occur naturally in soil, their poor availability (8) necessitates soil amendment with commercial fertilizers to supply phosphorus nutrition. Phosphonates are reduced phosphorus compounds with selective effectiveness against oomycetous fungi (4). The question has been raised whether phosphonates can replace phosphates as a source of phosphorus with the additional benefit of disease control (6). Currently, there are several commercial products that contain phosphonate (e.g., phosphite, the salt of phosphorous acid) as the phosphorus carrier. These products are registered as supplemental soil and foliar fertilizers for annual and perennial crops.

The goal of our study was to investigate and quantify plant growth responses following root application of selected phosphorus formulations and to determine their effects on plant susceptibility to Phytophthora root rot. Specifically, we wanted to determine if phosphorous acid or its salt, phosphite, can substitute for phosphate fertilization and support healthy plant development of tomato (Lycopersicon escu-

Corresponding author: J. E. Adaskaveg

E-mail: jim.adaskaveg@ucr.edu

Accepted for publication 16 July 1998.

Publication no. D-1998-0817-02R

(C) 1998 The American Phytopathological Society lentum L.) and green pepper (Capsicum annuum L.). Additionally, pepper plants that were grown with different phosphorus fertilizers were evaluated for disease incidence and severity of Phytophthora root and crown rot caused by Phytophthora capsici. A nutrient-film hydroponic culture system was selected for our investigations. Hydroponic culture provides plant roots with nutrients from defined solutions that contain less diverse and probably smaller populations of microorganisms than do soil systems (16). This may reduce the potential microbial oxidation of phosphorous acid to phosphoric acid (1). Furthermore, hydroponic systems have proven to be very useful in short-term studies for management of Phytophthora capsici on pepper (15).

\section{MATERIALS AND METHODS}

Hydroponic growing system for tomato and green pepper plants. Tomato (cv. Bonny Best Improved, Seminis Seed Company, Woodland, CA) and green pepper (cv. Joe Parker) plants were grown from seed in a root cube growth medium. For this, seeds were sown in $75 \mathrm{~mm}$ long plastic cylindrical culture tubes $(18 \mathrm{~mm}$ inner diameter) that were filled with a growth medium (Smithers-Oasis, Kent, $\mathrm{OH})$ and were immersed in water. The recirculating nutrient-film hydroponic system was set up in a greenhouse on the University of California-Riverside campus. The system was established on eight greenhouse benches. Six 3-m-long PVC pipes, $10 \mathrm{~cm}$ in diameter, were placed on each greenhouse bench. Seven evenly spaced sets of three holes were made in each of the six PVC pipes, and plant culture tubes were inserted. Seedlings of uniform size were selected and transferred into the hydroponic system after 10 to 14 days (=day 1 of the hydroponic experiment). After 1 week, two plants per set of three were removed to guarantee uniformity of plants. Nutrient solutions were pumped from a 40-liter reservoir for each bench through drip irrigation hoses that were connected to one end of each PVC tube using 3.8 liter/h emitters. Solutions were collected on the opposite end through drain holes and returned to the reservoir using drip irrigation hoses. Thus, each bench corresponded to one treatment.

Air temperature, relative humidity, leaf wetness, water temperature, and water electrical conductivity for each treatment were monitored every minute using electronic sensors and dataloggers (Campbell Scientific, Logan, UT). Data were summarized daily for average, maximum, and minimum values for each sensor.

Nutrient solutions. A basic nutrient solution was made using distilled water and the following compounds: $1.5 \mathrm{mM}$ $\mathrm{Ca}\left(\mathrm{NO}_{3}\right)_{2}, 2 \mathrm{mM} \mathrm{CaSO}{ }_{4}, 1.5 \mathrm{mM} \mathrm{MgSO}$, $43 \mu \mathrm{M}$ EDTA-Fe, and $0.1 \mathrm{ml}$ of a trace element solution $\left(0.208 \mu \mathrm{g}\right.$ of $\mathrm{BO}_{3} \mathrm{H}_{3}$, $0.028 \mu \mathrm{g}$ of $\mathrm{CuSO}_{4} \cdot 5 \mathrm{H}_{2} \mathrm{O}, 0.560 \mu \mathrm{g}$ of EDTA-Fe, $0.598 \mu \mathrm{g}$ of $\mathrm{MnSO}_{4} \cdot \mathrm{H}_{2} \mathrm{O}, 0.025$ $\mu \mathrm{g}$ of $\mathrm{Mo}_{7} \mathrm{O}_{24}\left(\mathrm{NH}_{4}\right)_{6} \cdot 4 \mathrm{H}_{2} \mathrm{O}$, and $0.337 \mu \mathrm{g}$ of $\mathrm{ZnSO}_{4} \cdot 7 \mathrm{H}_{2} \mathrm{O}$ per $\mathrm{ml}$ ) per liter. The seven nutrient solutions containing a final potassium content of $3 \mathrm{mM}$ are described as follows: (i) $1.5 \mathrm{mM} \mathrm{K}_{2} \mathrm{SO}_{4}$ for the no phosphorus solution, (ii) $1.45 \mathrm{mM} \mathrm{K} \mathrm{SO}_{4}$ and $0.1 \mathrm{mM} \mathrm{KH} \mathrm{KO}_{4}$ for the $0.1 \mathrm{mM}$ phosphate solution, (iii) $1 \mathrm{mM} \mathrm{K} \mathrm{SO}_{4}$ and $1 \mathrm{mM} \mathrm{KH}_{2} \mathrm{PO}_{4}$ for the $1 \mathrm{mM}$ phosphate solution, (iv) $1.43 \mathrm{mM} \mathrm{K}_{2} \mathrm{SO}_{4}$ and $38.7 \mu \mathrm{l}$ of technical phosphite stock solution per liter $(212 \mathrm{~g}$ of phosphorous acid per liter buffered to $\mathrm{pH} 6.4$ with $\mathrm{KOH}$ ) for the 0.1 $\mathrm{mM}$ phosphite solution, (v) $0.84 \mathrm{mM}$ $\mathrm{K}_{2} \mathrm{SO}_{4}$ and $386 \mu \mathrm{l}$ of technical phosphite stock solution per liter for the $1 \mathrm{mM}$ phosphite solution, (vi) $0.80 \mathrm{mM} \mathrm{K}_{2} \mathrm{SO}_{4}, 1$ $\mathrm{mM} \mathrm{KH}_{2} \mathrm{PO}_{4}$, and $116 \mu \mathrm{l}$ of technical phosphite stock solution per liter for the 1 $\mathrm{mM}$ phosphate/ $0.3 \mathrm{mM}$ phosphite solution, and (vii) $1 \quad \mathrm{mM}^{\mathrm{K}} \mathrm{K}_{2} \mathrm{SO}_{4}$ and $1 \mathrm{mM}$ phosphite (supplied as Nutri-Phite P Foliar, 4-30-8, Biagro Western Sales, Inc., Visalia, CA) for the commercial phosphite treatment. Technical phosphite (i.e., phospho- 
rous acid) was supplied by Rhône-Poulenc Ag Co. (Research Triangle Park, NC). The $\mathrm{pH}$ of each nutrient solution was adjusted to 5.5 using $3 \mathrm{~N} \mathrm{HCl}$. Nutrient solutions were changed twice during the tomato experiments (after 8 and 15 days) and twice during the pepper experiments (after 6 and 15 days). For this, the flow of the nutrient solutions was interrupted, the old solutions were drained from the tubes, and the nutrient reservoirs were filled with new solutions. Before continuing the experiment, the tubes were washed with the new solutions.

Inoculation of pepper plants with $\boldsymbol{P}$. capsici. Two procedures were used for inoculation. In the first experiment, $5 \mathrm{ml}$ of a zoospore suspension $(5,000$ zoospores per $\mathrm{ml}$ ) of $P$. capsici (isolate 6143 from green pepper plants, obtained from C. Liddell, New Mexico State University) was added on day 16 to each seedling in the hydroponic system. In the second experiment, a severely infected plant from the first experiment was left in the hydroponic system to serve as an inoculum source. The $0.1 \mathrm{mM}$ phosphate treatment was not inoculated and served as the control. Eight plants in a single replication were used for each treatment and for each experiment.

Harvest and measurements. Tomato plants (6 plants per treatment) or pepper plants (8 plants per treatment) were harvested 23 days after transferring them into the hydroponic system. For the determination of leaf areas, photographs of all leaves of four individual plants were taken, scanned into the computer using the program PHOTOSHOP version 4.0 (Adobe Systems, Inc., San Jose, CA), and the total leaf area per plant was calculated using the computer program Image-Pro Plus version
1.3 (Media Cybernetics, Silver Spring, MD). Dry weights for stems, leaves, and roots of tomato plants or shoots and roots of pepper plants were obtained after drying tissues for 2 days at $65^{\circ} \mathrm{C}$. Experiments using tomato plants were repeated three times in spring and summer using single replications of six plants per treatment. Experiments using single replications of eight pepper plants per treatment were done twice in the summer.

Disease evaluation. Disease incidence of $P$. capsici-inoculated green pepper plants was visually determined at the time when all inoculated control plants exhibited Phytophthora crown rot. This occurred approximately 2 weeks after inoculation in the first experiment and 4 weeks after inoculation in the second experiment. Tissue samples from roots or lower stems were used for reisolation of $P$. capsici on a

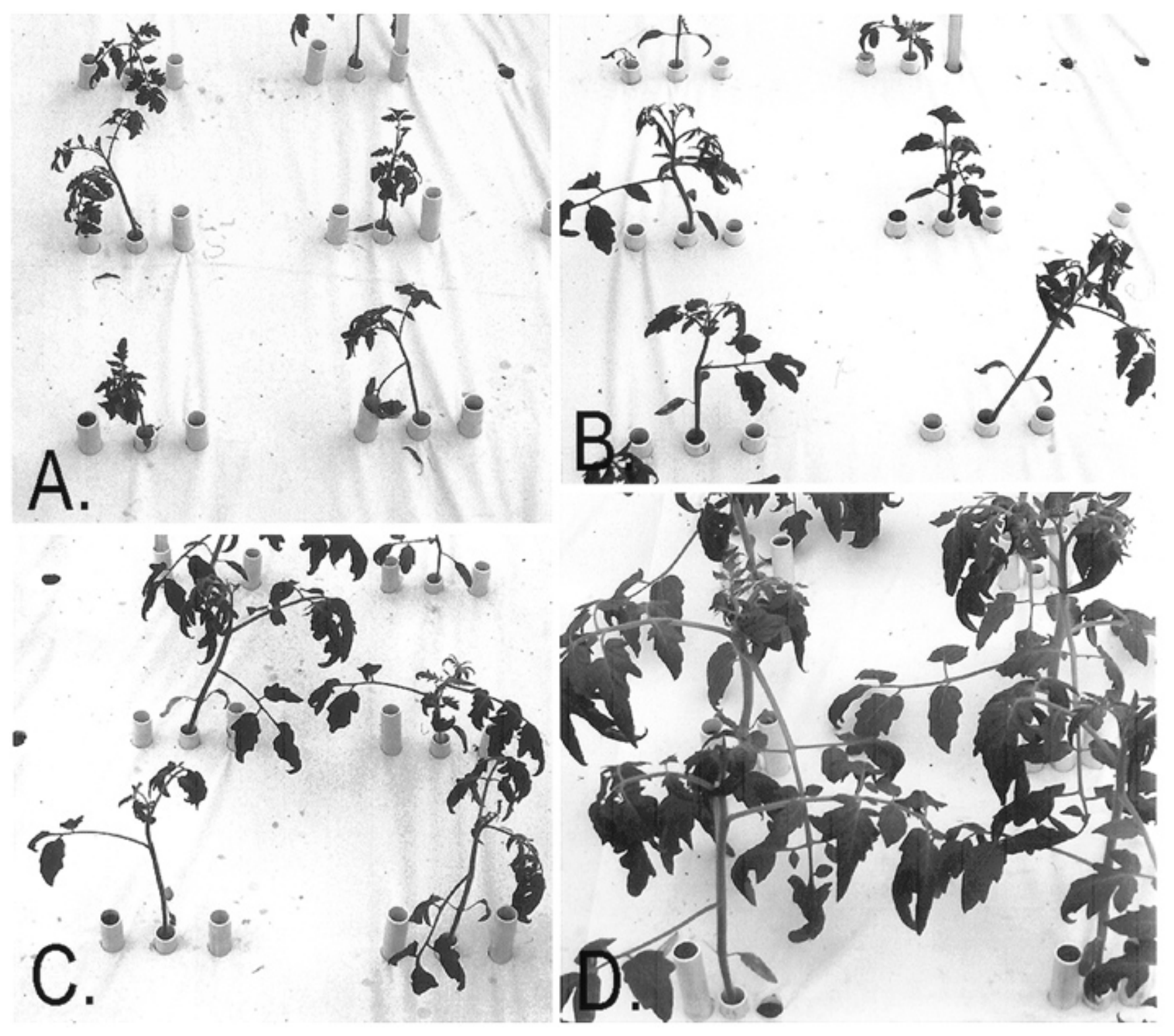

Fig. 1. Plant appearance 23 days after transferring tomato seedlings into the re-circulating hydroponic system. Treatments shown are: (A) no-phosphorus control, (B) commercial phosphite $(1 \mathrm{mM})$, (C) technical phosphite $(1 \mathrm{mM})$, and $(\mathbf{D})$ phosphate $(1 \mathrm{mM})$. Photographs are approximately one-tenth actual size. 
modified Kannwischer and Mitchell (5) medium (cornmeal agar containing $5 \mu \mathrm{g}$ of pimaricin, $50 \mu \mathrm{g}$ of rifampicin, $100 \mu \mathrm{g}$ of ampicillin, $100 \mu \mathrm{g}$ of $\mathrm{PCNB}$, and $50 \mu \mathrm{g}$ of hymexazol per $\mathrm{ml}$ ).

Phosphate analysis. For both tomato and pepper, samples were ground with mortar and pestle and passed through a $0.417-\mathrm{mm}$ sieve. Phosphate analysis of the nutrient solutions also was done before and after each nutrient solution change for the tomato experiments. Phosphate analyses were conducted by the DANR Analytical Laboratory (University of California, Davis).

Statistical analysis. For tomato growth parameters, three experiments were conducted, and the means of six plants per treatment per experiment were treated as replications in the statistical analysis. For leaf areas, data were available for only two experiments. For statistical analysis of phosphate concentrations of tomato plants, the dried leaf samples of the six plants used in the single replication of each treatment were combined, resulting in one composite leaf sample for each treatment of the three experiments. Statistical analysis of disease incidence of pepper plants was based on the means of eight plants from each of two experiments. Dry weights of pepper shoots were determined in only the second experiment. The mean dry weight of eight shoots per treatment was calculated, and no statistical analysis was performed. For phosphate analysis of pepper plants, dried shoot tissue of eight plants from the second experiment was combined, and no statistical analysis was conducted. Statistical analysis of phosphate levels before and after changing each nutrient solution was based on four samples, two each from two experiments. Data were analyzed using analysis of variance procedures, and multiple comparisons of means were performed using least significant difference (LSD) procedures of SAS 6.10 (SAS Institute, Cary, NC).

\section{RESULTS}

Growth responses of tomato plants grown with different phosphorus fertilizers. All plants in treatments with phosphite alone (technical or commercial grades of phosphite) exhibited foliar symptoms typical of phosphorus deficiency that were identical to symptoms of plants grown without phosphorus in the control treatment (Fig. 1). Foliar symptoms included darker green leaves and the accumulation of reddish to purplish (anthocyanin) pigments on the lower leaf surface.

Plant growth using phosphate as the only phosphorus source was significantly increased compared with the no-phosphorus control or plants supplied with phosphite alone (Figs. 1 and 2). There was a significant difference in stem dry weights between the two phosphate levels $(0.1 \mathrm{mM}$ or $1 \mathrm{mM})$, and a trend toward higher leaf and root dry weights as well as leaf area was observed for the $0.1 \mathrm{mM}$ phosphate
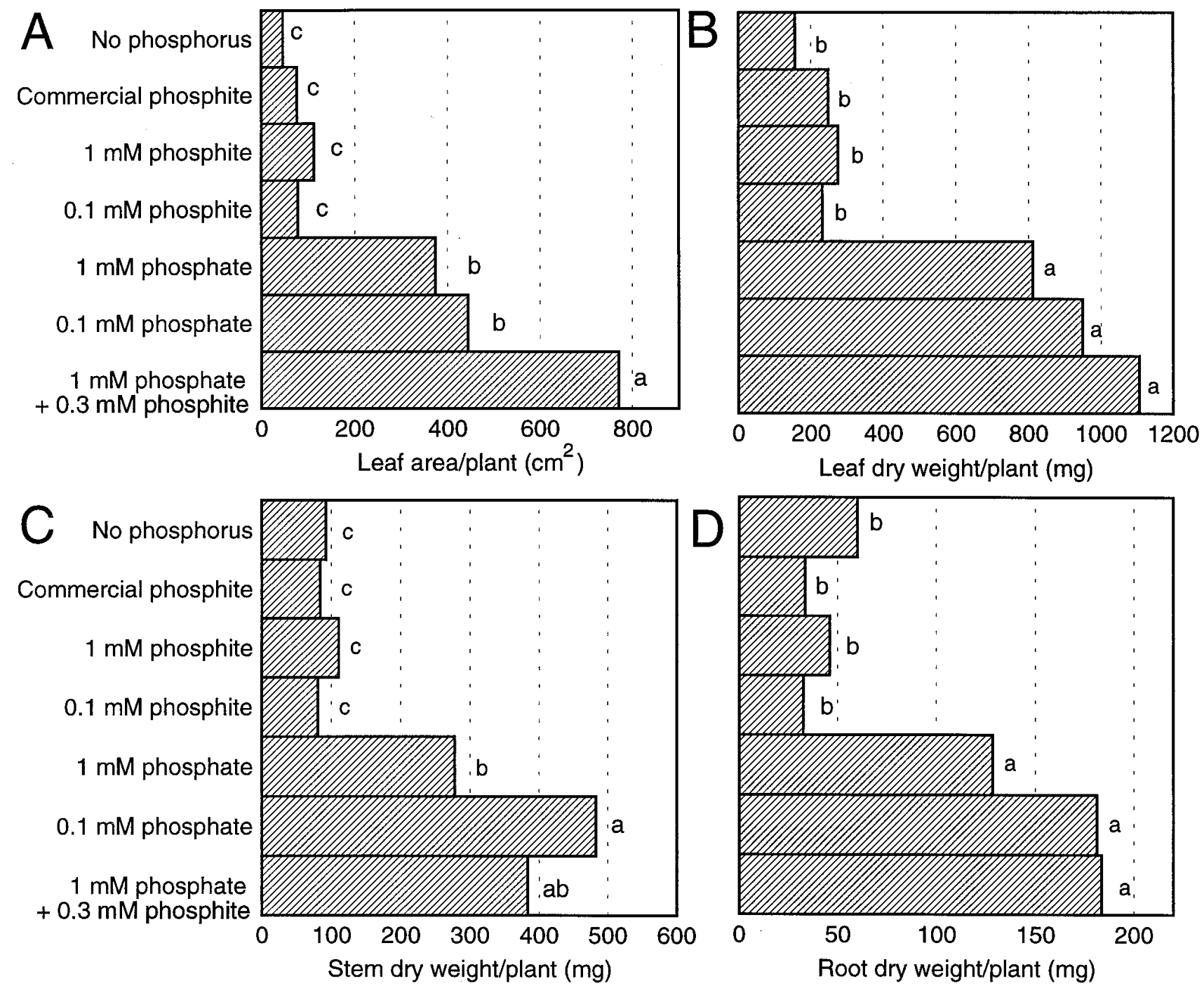

Fig. 2. Effect of different phosphorus sources on growth of tomato plants grown in a recirculating nutrient-film hydroponic system. Plants were harvested 23 days after transplanting seedlings into the hydroponic systems. (A) Leaf area, (B) leaf dry weights, (C) stem dry weights, and (D) root dry weights per plant were measured. Data are the average of six plants from each of three experiments conducted during the spring and summer. Bars with the same letter are not significantly different based on analysis of variance and least significant difference (LSD) mean separation $(P>0.05)$. 
treatment compared with the $1 \mathrm{mM}$ phosphate treatment. The combined $1 \mathrm{mM}$ phosphate $/ 0.3 \mathrm{mM}$ phosphorous acid treatment increased tomato leaf area significantly compared with all other treatments, and a trend was observed for higher leaf dry weight. For all phosphate treatments, values for leaf areas and dry weights of leaves, roots, and stems were approximately two- to fivefold higher compared with the phosphite and no-phosphorus control treatments (Fig. 2A to D). Plants $\mathrm{mM}$ ) had leaf areas and dry weights of leaf, stem, and root tissue similar to the nophosphorus control (Fig. 2A to D).

The root:shoot ratio (based on dry weights), with an average value of 0.25 , was highest for the no-phosphorus treatment compared with the other treatments. The various phosphorus fertilizers (phosphate or phosphite) decreased relative that were fertilized with phosphite $(0.1$ or 1

root:shoot growth between 57.5 and $45.5 \%$ compared with the no-phosphorus treatment.

Average and maximum/minimum environmental parameters for the three experiments were: $22.3^{\circ} \mathrm{C}, 27.9 / 17.9^{\circ} \mathrm{C}$ air temperature; $76.5 \%, \quad 86.7 / 60 \%$ relative humidity; $23.5^{\circ} \mathrm{C}, 28.3 / 20.1^{\circ} \mathrm{C}$ water temperature; and $1.41 \mathrm{mS} / \mathrm{cm}, 1.9 / 1.1 \mathrm{mS} / \mathrm{cm}$ temperature-corrected electrical conductivity.

Growth responses of pepper plants grown with different phosphorus fertilizers. Growth responses of pepper were similar to those of tomato plants, and differences were observed between the phosphate and phosphite or no-phosphorus treatments. Shoot dry weights averaged 4,626.3 $\pm 2,124.9 \mathrm{mg}, 332.4 \pm 205.9 \mathrm{mg}$, and $190.7 \pm 91.5 \mathrm{mg}$ per plant for phosphate- and phosphate/phosphite-treated plants, phosphite-treated, and no phospho-

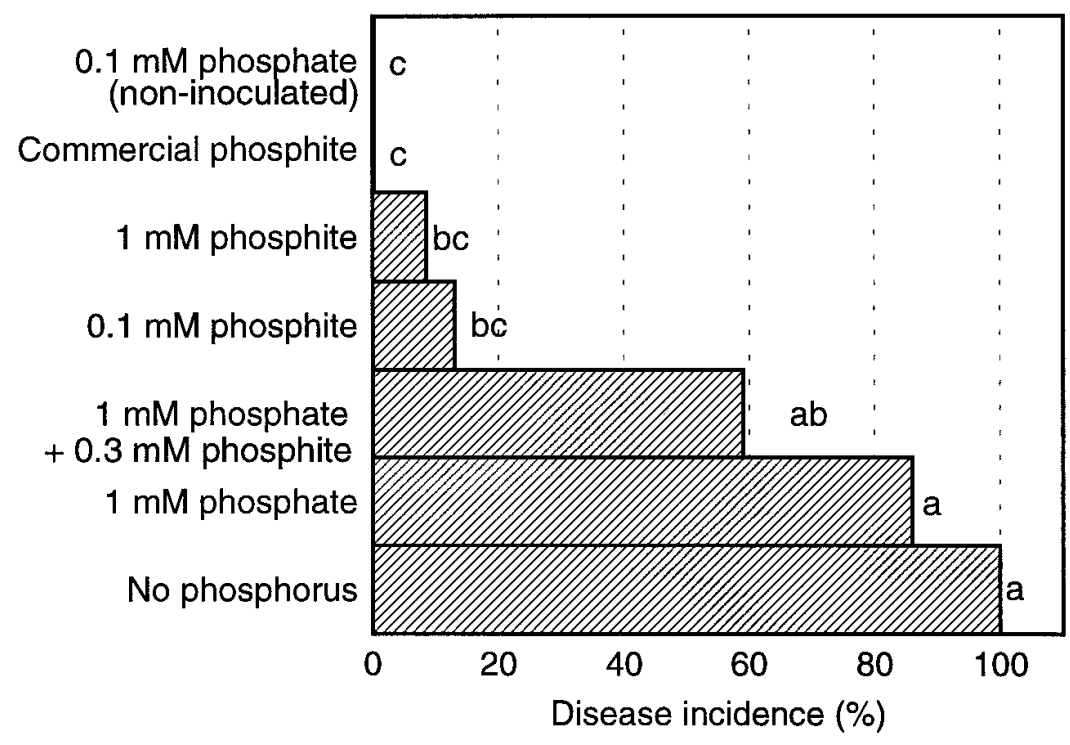

Fig. 3. Effect of different phosphorus sources on the incidence of Phytophthora root and crown rot of green pepper plants grown in a recirculating nutrient-film hydroponic system. Plants were inoculated with Phytophthora capsici and evaluated when all inoculated control (no phosphorus) plants had crown rot. The $0.1 \mathrm{mM}$ phosphate treatment was not inoculated. Data are the average of two experiments (replications) representing the means of eight plants per experiment. Bars with the same letter are not significantly different based on analysis of variance and least significant difference (LSD) mean separation $(P>0.05)$.

Table 1. Phosphate concentrations $(\mathrm{mg} / \mathrm{ml})$ in tomato and pepper plants and in nutrient solutions of the hydroponic culture system

\begin{tabular}{|c|c|c|c|c|}
\hline \multirow[b]{2}{*}{ Treatment $^{w}$} & \multirow{2}{*}{$\begin{array}{l}\text { Tomato } \\
\text { leaves }^{x}\end{array}$} & \multirow{2}{*}{$\begin{array}{l}\text { Pepper } \\
\text { shoots }^{y}\end{array}$} & \multicolumn{2}{|c|}{ Nutrient solutions ${ }^{\mathrm{z}}$} \\
\hline & & & Fresh & Old \\
\hline No phosphorus & $753.3 \mathrm{~d}$ & 475.0 & $0.2 \mathrm{~d}$ & $0.3 \mathrm{~b}$ \\
\hline $1 \mathrm{mM}$ commercial formulation of phosphite & $2,940.0 \mathrm{c}$ & $1,953.3$ & $0.3 \mathrm{~d}$ & $0.5 \mathrm{~b}$ \\
\hline $1 \mathrm{mM}$ phosphite & $1,616.7 \mathrm{~cd}$ & $2,203.3$ & $0.4 \mathrm{~d}$ & $0.6 \mathrm{~b}$ \\
\hline $0.1 \mathrm{mM}$ phosphite & $883.3 \mathrm{~d}$ & $1,146.7$ & $0.1 \mathrm{~d}$ & $0.3 \mathrm{~b}$ \\
\hline $1 \mathrm{mM}$ phosphate & $7,123.3 \mathrm{a}$ & $3,976.7$ & $31.4 \mathrm{a}$ & $30.5 \mathrm{a}$ \\
\hline $0.1 \mathrm{mM}$ phosphate & $4,930.0 \mathrm{~b}$ & ND & $3.5 \mathrm{c}$ & $2.4 \mathrm{~b}$ \\
\hline $1 \mathrm{mM}$ phosphate $+0.3 \mathrm{mM}$ phosphite & $5,380.0 \mathrm{~b}$ & $3,266.7$ & $27.7 \mathrm{~b}$ & $31.4 \mathrm{a}$ \\
\hline
\end{tabular}

${ }^{\mathrm{w}}$ Treatment means followed by the same letter are not significantly different based on analysis of variance (ANOVA) and least significant difference (LSD) test $(P>0.05)$.

${ }^{\mathrm{x}}$ Means of one leaf sample from each of four tomato experiments.

${ }^{y}$ Means of eight shoots (one replication) per treatment from the second experiment. Phosphate analysis of the $0.1 \mathrm{mM}$ phosphate treatment of peppers was not done (ND).

${ }^{\mathrm{z}}$ Means of four samples from four experiments. rus-treated plants, respectively. Root dry weights averaged $860.8 \pm 608.9 \mathrm{mg}, 75.2 \pm$ $93.0 \mathrm{mg}$, and $69.9 \pm 51.9 \mathrm{mg}$ per plant for phosphate- and phosphate/phosphitetreated plants, phosphite-treated, and no phosphorus-treated plants, respectively. No difference was observed in shoot or root dry weights for plants treated with the commercial form of phosphite compared with plants treated without phosphorus.

Average and maximum/minimum environmental parameters for both pepper experiments were: $23.3^{\circ} \mathrm{C}, 28.6 / 19.5^{\circ} \mathrm{C}$ air temperature; $75.5 \%, 85.5 / 58.4 \%$ relative humidity; $25.1^{\circ} \mathrm{C}, 28.2 / 22.6^{\circ} \mathrm{C}$ water temperature; and $1.51 \mathrm{mS} / \mathrm{cm}, 1.76 / 1.47$ $\mathrm{mS} / \mathrm{cm}$ temperature-corrected electrical conductivity.

Disease evaluation of $P$. capsici-inoculated pepper plants. Disease symptoms on pepper caused by $P$. capsici consisted of discolored roots and girdling dark lesions on the hypocotyls (i.e., crown rot) that generally resulted in the death of the plant. Crown rot incidence was significantly lower $(P<0.05)$ in plants supplied with either phosphite formulation as a phosphorus source compared with the nophosphorus or phosphate-treated plants (Fig. 3). Plants that were fertilized with a phosphate $(1 \mathrm{mM}) /$ phosphite $(0.3 \mathrm{mM})$ combination exhibited an intermediate response between the high susceptibility of phosphate- and no phosphorus-treated plants and the low disease incidence observed among plants treated with any formulation of phosphite (Fig. 3). Between 2 and 4 weeks after inoculation in both experiments, plants treated with no phosphorus died, and disease incidence generally increased in both phosphate- and phosphite-treated plants. Most of the plants treated with the commercial form of phosphorous acid, however, still appeared healthy after 4 weeks. Root/lower stem (below crown) isolations resulted in the consistent recovery of $P$. capsici from all treatments except the noninoculated 0.1 $\mathrm{mM}$ phosphate-treated plants.

Phosphate concentrations in nutrient solutions. There was no difference in phosphate concentration between the nophosphorus and phosphite treatments (Table 1). Phosphate concentrations in the $1 \mathrm{mM}$ phosphate or $1 \mathrm{mM}$ phosphate/0.3 $\mathrm{mM}$ phosphite treatments were highest and were approximately 10 -fold higher compared with the $0.1 \mathrm{mM}$ phosphate solution. No significant change $(P>0.05)$ in phosphate concentration was found in solutions that had circulated for 6 to 8 days in the hydroponic system compared with freshly prepared solutions.

Phosphate concentrations in tomato and green pepper plants. Phosphate concentrations in tomato leaves were significantly $(P<0.05)$ higher for the phosphatetreated plants than for leaves in all other treatments (Table 1). Phosphate concentrations in leaves of plants treated with the 
commercial formulation of phosphite were significantly higher than those of the nophosphorus-treated and the $0.1 \mathrm{mM}$ phosphite-treated plants. The amount of root tissue available for phosphite-treated and no-phosphorus-treated plants generally was not sufficient for a phosphate analysis, and therefore root analyses were not done. Similar results for phosphate concentrations were found for the pepper plants (Table 1).

\section{DISCUSSION}

One of the objectives of this research was to evaluate the effect of phosphorous acid formulations on plant development compared with phosphate treatments. Our results demonstrated that phosphite-treated tomato and pepper plants were deficient in phosphate and developed phosphorus-deficiency symptoms when grown hydroponically from seedlings to early plant development (approximately 3 weeks). Growth of plants that were fertilized with phosphorous acid or its commercial form (NutriPhite) was much reduced compared with growth of plants supplemented with phosphate. This is in agreement with previous findings using potted plants (7). Severe phosphorus starvation was also evident in the no-phosphorus control plants. In our study, growth parameters of plants growing in $0.1 \mathrm{mM}$ phosphate were either higher or not significantly different from plants growing in $1 \mathrm{mM}$ phosphate. Wilcox (17) indicated that phosphorus levels in whole plant tops were $3,500 \mu \mathrm{g} / \mathrm{g}$ for an adequate nutrient concentration and $2,800 \mu \mathrm{g} / \mathrm{g}$ in deficient tomato seedlings 24 to 31 days after emergence. In our study, the $1.0 \mathrm{mM}$ phosphate treatment had a concentration of over 7,000 $\mu \mathrm{g} / \mathrm{g}$ (Table 1). Although nutrient toxicity of phosphorus and other macronutrients is rare, Bennett (2) indicated that these plant nutrients, if taken up in excess, will often cause imbalances with other nutrients and will result in poor plant growth. Thus, the high levels of phosphate in plants grown in the $1.0 \mathrm{mM}$ phosphate treatment may explain significantly reduced stem dry weights and leaf area, as well as lower leaf and root dry weights compared with plants grown in the $0.1 \mathrm{mM}$ phosphate treatment.

Evaluating the effect of combined phosphate/phosphite nutrition, Carswell et al. (3) found that the addition of phosphite (1.5 to $10 \mathrm{mM}$ ) to phosphate-limited Brassica nigra seedlings reduced plant growth, whereas with phosphate-sufficient plants only the $10 \mathrm{mM}$ phosphite levels caused such a reduction. In addition, while root:shoot ratios of phosphate-stressed plants were typically high $(3,11,13)$, phosphite supplementation decreased the root:shoot ratio to about $40 \%$ of control values. These effects were explained by Carswell et al. (3) as a disruption of the phosphate-starvation response by phosphonates in which the phosphate-limited plants function as though they are phosphorus-sufficient. In our study, root:shoot ratios of tomato plants were also much lower for the phosphorous acid-fertilized plants compared with the no-phosphorus plants, indicating similar effects on phosphate metabolism. In our study, however, a combined $1 \mathrm{mM}$ phosphate $/ 0.3 \mathrm{mM}$ phosphorous acid treatment increased leaf area significantly in two experiments where this parameter was measured, and a trend was observed for greater leaf dry weight compared with phosphate treatment alone in three experiments. This finding might explain the registered label of commercial formulations of phosphite as supplemental fertilizers for improved plant growth and increased crop yield. Additional studies are needed to evaluate possible interactions between phosphite and phosphate fertilizers.

Phosphorous acid is readily taken up by the plant and is xylem- and phloem-mobile (10). Using ion chromatography for phosphorous acid quantification, Ouimette and Coffey (10) demonstrated that phosphonates appear to be quite stable in avocado plants, persisting in this form for at least several months. Similarly, Robertson and Boyer (12) reported a biological inertness of organic and inorganic phosphites. In our experiments, phosphate concentrations of tomato plants treated with technical phosphite did not differ statistically from those of the no-phosphorus control plants. Phosphate levels in the solutions were not significantly different $(P>0.05)$ when freshly made or after 1 week in the recirculating hydroponic system, supporting previous work that in aqueous solutions, molecular oxygen does not readily oxidize phosphonates (12). A general trend for higher phosphate levels, however, was observed in the $1.0 \mathrm{mM}$ phosphite solutions compared with the no-phosphorus treatment. For fresh or old solutions, measurable levels of phosphate in the nophosphorus and the $1 \mathrm{mM}$ phosphite treatments ranged from 0.2 to $0.6 \mu \mathrm{g} / \mathrm{ml}$, respectively. Contamination could have occurred from the salts used for the basic nutrient solution. In plants treated with a commercial formulation of phosphite, phosphate concentrations were significantly above those of the no-phosphorus treated plants. This increase could be explained by the slightly increased phosphate levels in the nutrient solution. Decreased phosphate concentrations in plant tissue of the $1 \mathrm{mM}$ phosphate $/ 0.3 \mathrm{mM}$ phosphite treated plants relative to the $1 \mathrm{mM}$ phosphate treated plants is in agreement with previous studies that showed that growth of phosphate-sufficient plants in the presence of phosphite caused a reduction in root and leaf phosphate levels (3).

The effect of phosphorus compounds on disease control was studied using $P$. capsici-inoculated pepper plants. Plants grown with both formulations of phosphorous acid had significantly less Phytophthora crown rot compared with the no-phosphorus or phosphate-treated plants. This observation supports a number of studies dealing with phosphonates as antifungal compounds against oomycetous fungi $(9,14)$. Although $P$. capsici was isolated from plants treated with the commercial formulation of phosphite, disease symptoms were not observed in most of the plants over the experimental period of 4 weeks. Therefore, the commercial form of phosphorous acid (Nutri-Phite) had additional benefits in reducing Phytophthora root rot compared with technical phosphorous acid. The reason for this is unknown. However, undeclared ingredients in the commercial formulation may be responsible.

This is the first report that demonstrated that technical and commercial formulations of phosphite significantly reduced the incidence of Phytophthora root and crown rot of pepper but did not provide sufficient phosphorus nutrition to tomato and pepper plants when used as sole sources of phosphorus in a recirculating hydroponic system.

\section{ACKNOWLEDGMENTS}

We thank K. Conn for supplying tomato seeds, N. Goldberg for supplying pepper seeds, C. Liddell for providing an isolate of $P$. capsici, and C. Huang for her excellent technical assistance.

\section{LITERATURE CITED}

1. Adams, F., and Conrad, J. P. 1953. Transition of phosphite to phosphate in soils. Soil Sci. 75:361-371.

2. Bennett, W. F. 1993. Plant nutrient utilization and diagnostic plant symptoms. Pages 1-7 in: Nutrient Deficiencies and Toxicities in Crop Plants. W. Bennett, ed. American Phytopathological Society, St. Paul, MN.

3. Carswell, C., Grant, B. R., Theodorou, M. E., Harris, J., Niere, J. O., and Plaxton, W. C. 1996. The fungicide phosphonate disrupts the phosphate-starvation response in Brassica nigra seedlings. Plant Physiol. 110:105-110.

4. Coffey, M. D., and Ouimette, D. G. 1989. Phosphonates: Antifungal compounds against oomycetes. Pages 107-129 in: Nitrogen, Phosphorus and Sulphur Utilization by Fungi. Symposium of the British Mycological Society, April 1988. L. Boddy, R. Marchant and D. J. Reed, eds. Cambridge University Press, Cambridge

5. Kannwischer, M. E., and Mitchell, D. J. 1978. The influence of a fungicide on the epidemiology of black shank of tobacco. Phytopathology 68:1760-1765

6. Lovatt, C. J. 1990. A definitive test to determine whether phosphite fertilization can replace phosphate fertilization to supply $\mathrm{P}$ in the metabolism of 'Hass' on 'Duke 7'. Calif. Avocado Soc. Yearb. 74:61-64.

7. MacIntire, W. H., Winterberg, S. H., Hardin, L. J., Sterges, A. J., and Clements, L. B. 1950 Fertilizer evaluation of certain phosphorus, phosphorous, and phosphoric materials by means of pot cultures. Agron. J. 42:543-549.

8. Mengel, K., and Kirkby, E. A. 1987. Principles of Plant Nutrition. International Potash Institute, Worblaufen-Bern, Switzerland.

9. Ouimette, D. G., and Coffey, M. D. 1989 Phosphonate levels in avocado (Persea americana) seedlings and soil following treatment with fosetyl-Al or potassium phosphonate. Plant Dis. 73:212-215. 
10. Ouimette, D. G., and Coffey, M. D. 1990. Symplastic entry and phloem translocation of phosphonate. Pestic. Biochem. Physiol. 38:18-25.

11. Rabe, E., and Lovatt, C. J. 1986. Increased arginine biosynthesis during phosphorus deficiency. A response to the increased ammonia content of leaves. Plant Physiol. 81:774-779.

12. Robertson, H. E., and Boyer, P. D. 1956. The biological inactivity of glucose 6-phosphite, inorganic phosphites and other phosphites.
Arch. Biochem. Biophysics 62:380-395.

13. Rychter, A. M., and Mikulska, M. 1990. The relationship between phosphate status and cyanide-resistant respiration in bean roots. Physiol. Plant. 79:663-667.

14. Smillie, R., Grant, B. R., and Guest, D. 1989. The mode of action of phosphite: Evidence for both direct and indirect modes of action on three Phytophthora spp. in plants. Phytopathology 79:921-926.

15. Stanghellini, M. E., Kim, D. H., Rasmussen,
S. L., and Rorabaugh, P. A. 1996. Control of root rot of peppers caused by Phytophthora capsici with a nonionic surfactant. Plant Dis. 80:1113-1116.

16. Stanghellini, M. E., and Rasmussen, S. L. 1994. Hydroponics: A solution for zoosporic pathogens. Plant Dis. 78:1129-1138.

17. Wilcox, G. E. 1993. Tomato. Pages 137-141 in: Nutrient Deficiencies and Toxicities in Crop Plants. W. Bennett, ed. American Phytopathological Society, St. Paul, MN 